\begin{tabular}{|l|l|l|}
\hline \multicolumn{2}{|c|}{ PublisherInfo } \\
\hline \hline PublisherName & $:$ & BioMed Central \\
\hline \hline PublisherLocation & $:$ & London \\
\hline \hline PublisherImprintName & $:$ & BioMed Central \\
\hline \hline
\end{tabular}

\title{
Articles selected from Faculty of 1000 in June 2002
}

\begin{tabular}{||l|l|l||}
\hline \multicolumn{2}{|c||}{ ArticleInfo } \\
\hline \hline ArticleID & $:$ & 546 \\
\hline \hline ArticleDOI & $:$ & $10.1186 /$ bcr545 \\
\hline \hline ArticleCitationID & $:$ & E1 \\
\hline \hline ArticleSequenceNumber & $:$ & 12 \\
\hline \hline ArticleCategory & $:$ & Article selection \\
\hline ArticleFirstPage & $:$ & 1 \\
\hline \hline ArticleLastPage & $:$ & 2 \\
\hline \hline & $:$ & RegistrationDate : 2002-7-8 \\
ArticleHistory & $:$ & OnlineDate \\
\hline \hline ArticleCopyright & $:$ & BioMed Central Ltd2002-7-8 \\
\hline \hline ArticleGrants & $:$ & \\
\hline \hline ArticleContext & $:$ & 130584455 \\
\hline \hline
\end{tabular}


Breast Cancer Research Editorial, ${ }^{\text {Affl }}$

Corresponding Affiliation: Aff1

Email: editorial@breast-cancer-research.com

Aff1 Breast Cancer Research, BioMed Central Ltd, Middlesex House, 34-42

Cleveland Street, London W1T 4LB, UK

\section{Articles selected from Faculty of 1000}

\section{References}

1. Auman HJ, Nottoli T, Lakiza O, Winger Q, Donaldson S, Williams T: Transcription factor AP-2gamma is essential in the extra-embryonic lineages for early postimplantation development. Development. 2002, 129: 2733-2747. For the Faculty of 1000 evaluation of this article please see http://breast-cancer-research.com/reports/bcr7_02.asp\#auman

2. Offterdinger M, Schofer C, Weipoltshamme K, Grunt TW: c-erbB-3: a nuclear protein in mammary epithelial cells. J Cell Biol. 2002, 157: 929-940. For the Faculty of 1000 evaluation of this article please see http://breast-cancer-research.com/reports/bcr7_02.asp\#offterdinger

3. Urano T, Saito T, Tsukui T, Fujita M, Hosoi T, Muramatsu M, Ouchi Y, Inoue S: Efp targets 14-3-3sigma for proteolysis and promotes breast tumour growth. Nature. 2002, 417: 871-875. For the Faculty of 1000 evaluation of this article please see http://breast-cancer-research.com/reports/

bcr7_02.asp\#urano

This PDF file was created after publication. 